\title{
A novel technique in placing a Fogarty catheter in the upper limb of a Montgomery T-tube for a patient undergoing tracheal resection
}

\author{
David T. Wong, MD · Jacqueline A. Woo • \\ Patrick J. Gullane, MB
}

Received: 28 May 2009/Accepted: 8 December 2009/Published online: 20 January 2010

(C) Canadian Anesthesiologists' Society 2010

\section{To the Editor:}

A number of ventilation strategies exist for patients with Montgomery $\mathrm{T}$-tubes during tracheal resection. We describe a novel technique with antegrade passage of a Fogarty catheter through the mouth, guided by a suture to the upper limb of the T-tube. Written consent for publication of this article was obtained from the patient.

A 59-yr-old female patient (weight $89 \mathrm{~kg}$, height $173 \mathrm{~cm}$ ) diagnosed with idiopathic tracheal stenosis was scheduled to undergo tracheal resection. A computed tomography scan of her neck showed tracheal stenosis $1.3 \mathrm{~cm}$ in length located $1.5 \mathrm{~cm}$ below the glottis. In the operating room, standard monitoring was applied and the patient was anesthetized with remifentanil, propofol bolus and infusion, and rocuronium. The patient's lungs were ventilated with $100 \%$ oxygen with bag and mask for two minutes. Serial rigid bronchoscopies were performed up to $8.0 \mathrm{~mm}$, and a size $6.5 \mathrm{~mm}$ (internal diameter) armoured tracheal tube was inserted into the trachea under direct laryngoscopy.

The surgeons proceeded with a 3-cm cricotracheal resection with thyrotracheal anastomosis. During the resection, the patient's lungs were ventilated with an armoured tracheal tube attached to the distal trachea just

\footnotetext{
D. T. Wong, MD ( $\square)$

Toronto Western Hospital, University of Toronto,

Toronto, ON, Canada

e-mail: david.wong@uhn.on.ca

J. A. Woo

Queen's University, Kingston, ON, Canada

P. J. Gullane, MB

Toronto General Hospital, University of Toronto,

Toronto, ON, Canada
}

below the second ring. Later, during the anastomosis, the armoured tracheal tube was removed from the distal trachea. A size $11 \mathrm{~mm}$ (outer diameter) Montgomery T-tube (LT-511) (E. Benson Hood Laboratories, Inc, Pembroke, MA, USA) was inserted into the trachea to serve as a stent, and thyrotracheal anastomosis was performed.

As positive pressure ventilation of the lungs was required until the anastomosis was fully completed, a 15-mm connector was attached to the extratracheal limb of the T-tube to connect the ventilation circuit. In order to seal off the supraglottic leak through the upper limb of the T-tube, the following novel technique was used to pass a Fogarty catheter into the upper limb of the T-tube: Immediately after incision of the trachea, a suture was attached to the Murphy's eye of the tracheal tube. The tracheal tube was partially withdrawn during the tracheal resection; then, as the surgeons were ready to insert the T-tube, the tracheal tube was completely withdrawn and the suture to the Murphy's eye was cut. Next, the proximal end of the suture was tied to the tip of the Fogarty occlusion catheter (Model 62080814F) (Edwards Lifesciences LLC, Irvine, CA, USA) just distal to the balloon. The distal end of the suture was pulled slowly by the surgeon, and the Fogarty catheter was advanced through the mouth and glottis and positioned in the upper limb of the T-tube under direct visual guidance (Figure 1). Then, the balloon of the Fogarty catheter was inflated to provide an occlusive seal. A $15-\mathrm{mm}$ connector was inserted into the extratracheal limb and positive pressure ventilation was commenced. At the end of surgery, inhalational anesthesia was discontinued and muscle relaxation was reversed. The patient awoke and breathed spontaneously. The 15-mm connector was disconnected from the extratracheal limb of the T-tube, and an oxygen mask was placed over both the extratracheal limb of the T-tube and the patient's face. 
Fig. 1 a A suture was tied securely to the tip of a Fogarty catheter just distal to the balloon. b The suture was pulled slowly causing the Fogarty catheter to advance intraorally through the glottis into the surgical field. Then the suture was cut and removed. c The Fogarty catheter was positioned in the upper limb of the T-tube under direct visual guidance. Subsequently, the Fogarty balloon was inflated to provide upper limb occlusion.

$\mathrm{GL}=$ glottis

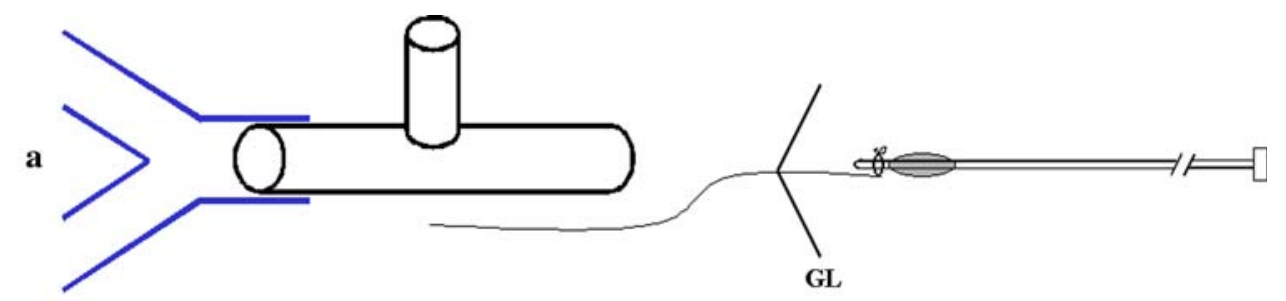

b
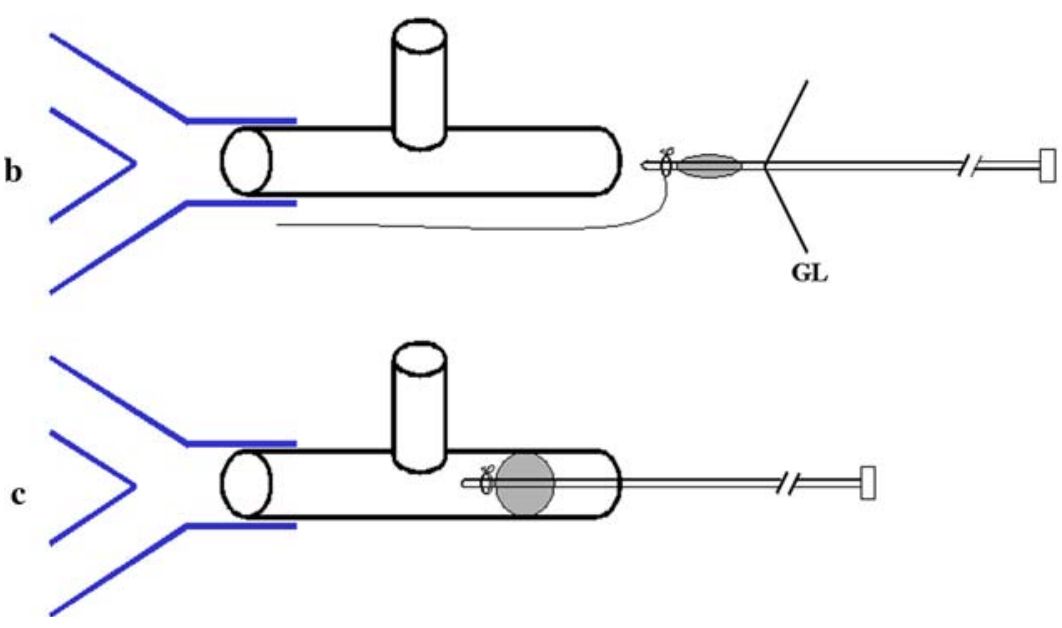

With the T-tube in situ, different strategies may be used to provide effective positive pressure lung ventilation during the course of tracheal resection. The first method involves the passage of a small tracheal tube through both upper and lower limbs of the T-tube. ${ }^{1}$ A second method involves the occlusion of the extratracheal limb of the T-tube by a clamp, while ventilation is maintained through the upper limb using a face mask, high frequency jet ventilation, or a supraglottic airway., ${ }^{2,3}$ A third method involves the occlusion of the upper limb with a pharyngeal pack, supraglottic airway, or Fogarty catheter, while ventilating the extratracheal limb of the T-tube. ${ }^{4,5}$ Montgomery suggested the retrograde passage of a Fogarty catheter through the extratracheal limb of the T-tube to occlude the upper limb while ventilation is provided via the extratracheal limb of the T-tube. ${ }^{6}$

A number of ventilation strategies exist for patients with T-tubes during tracheal resection. We describe a novel technique with antegrade passage of a Fogarty catheter through the mouth, guided by a suture, to the upper limb of the T-tube. This technique of upper limb occlusion may be more secure compared to a throat pack or surpaglottic airway.

Conflicts of interest None declared.

\section{References}

1. Ní Chonchubhair A, O'Connor T, O'Hagan C. A novel approach to insertion of Montgomery T-tube. Anaesthesia 1994; 49: 605-7.

2. Mather CM, Sinclair R, Gurr P. Tracheal stents: the Montgomery T-tube. Anesth Analg 1993; 77: 1282-4.

3. Wahidi MM, Ernst A. The Montgomery T-tube tracheal stent. Clin Chest Med 2003; 24: 437-43.

4. Agrawal S, Payal YS, Sharma JP, Meher R, Varshney S. Montgomery T-tube: anesthetic management. J Clin Anesth 2007; 19: 135-7.

5. Uchiyama M, Yoshino A. Insertion of Montgomery T-tube. Anaesthesia 1995; 50: 476-7.

6. Montgomery WW. Manual for care of Montgomery silicone tracheal T-tube. Ann Otol Rhinol Laryngol Suppl 1980; 89: 1-8. 